\title{
Seasonal distribution of aerosol properties over Europe and their impact on UV irradiance
}

\author{
N. Y. Chubarova \\ Faculty of Geography, Moscow State University, Moscow, Russia \\ Received: 1 July 2009 - Published in Atmos. Meas. Tech. Discuss.: 4 August 2009 \\ Revised: 1 October 2009 - Accepted: 3 October 2009 - Published: 26 October 2009
}

\begin{abstract}
Using the aerosol optical thickness at $550 \mathrm{~nm}$ ( $\left.\tau_{550}\right)$ from MODIS (collection 5) for the 2000-2008 period combined with the aerosol products from the groundbased AERONET network since 1996, monthly mean values of key aerosol parameters have been obtained with 1 degree resolution over Europe. Additional tests have revealed a satisfactory quality of the MODIS data, except in a few cases. Quality assured AERONET data are used for evaluating the Angstrom exponent, single scattering albedo and asymmetry factor, and for validating the final aerosol optical thickness in the UV spectral region. A method for extrapolating the aerosol parameters into the UV spectral region is discussed. The aerosol optical thickness distributions are considered together with meteorological fields from NOAA_NCEP_CPC_CAMS_OPI climatology. The $\tau_{340}$ is shown to vary significantly from approximately 0.01 to 0.9 depending on the season and location. Permanent elevated aerosol loading over several industrial areas is observed, which agrees with the output of chemical transport models. Using radiative transfer modeling, monthly mean UV loss due to aerosol was estimated. The absolute decrease in UV indices varies from less than 0.1 to 1.5. The relative UV attenuation has large spatial and temporal variations $(-1 \%-$ $-17 \%$ ) with a minimum towards the northwest and maxima over several southern local areas (Northern Italy, etc.) during the warm period.
\end{abstract}

\section{Introduction}

Atmospheric aerosols are one of the important factors influencing solar UV irradiance, which play an important role in the biosphere and have a strong impact on human health (Van

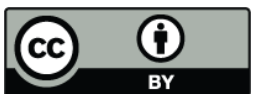

Correspondence to: N. Y. Chubarova (chubarova@imp.kiae.ru) der Leun et al., 1998). Therefore, it is necessary to have reliable spatial and temporal distribution of aerosol parameters to get proper UV estimates. The information on aerosol is also necessary for correcting satellite UV retrievals, which can overestimate the measurements up to $40 \%$ (McKenzie et al., 2001; Chubarova et al., 2005). The objective of this study is to develop the aerosol climatology over Europe and to characterize the aerosol effects on erythemally-weighted UV irradiance $\left(Q_{e}\right)$ reaching the ground.

Aerosol properties of the atmosphere can be obtained from both space and ground. At present several aerosol products are available from different satellite sensors (i.e. AVHRR, OMI, MODIS, CERES, AATSR, MERIS, GLAS, SeaWiFs, MISR) as well as from ground-based aerosol networks (AERONET/PHOTONS, SKYNET, AEROSIBNET, GLOBE, etc.) (IPCC, 2007). However, it is necessary to emphasize that the development of the aerosol climatology requires long-term period of observations and should have good spatial resolution. Unfortunately, only several aerosol datasets at present can satisfy these conditions. In addition, since most of aerosol measurements are being carried out in visible spectral range, another problem can arise, how to extrapolate the aerosol parameters to UV spectral region. It should be also noted that recently a new aerosol dataset from OMI satellite instrument has been developed providing the estimation of aerosol parameters directly in the UV spectral region (Torres et al., 2002). However, not very long period of observations (since 2004) and current problems with cloud screening procedures over Europe with prevailing cloudy conditions do not allow us to apply these records in our study.

The approach used in this study is based on the application of the data from satellite measurements of $\tau_{\lambda}$ at $550 \mathrm{~nm}\left(\tau_{550}\right)$ from Moderate Resolution Imaging Spectrometer (MODIS) (collection 5) combined with the aerosol products from ground-based aerosol network AERONET/PHOTONS over Europe. According to Remer et al. (2008), the latest MODIS

Published by Copernicus Publications on behalf of the European Geosciences Union. 


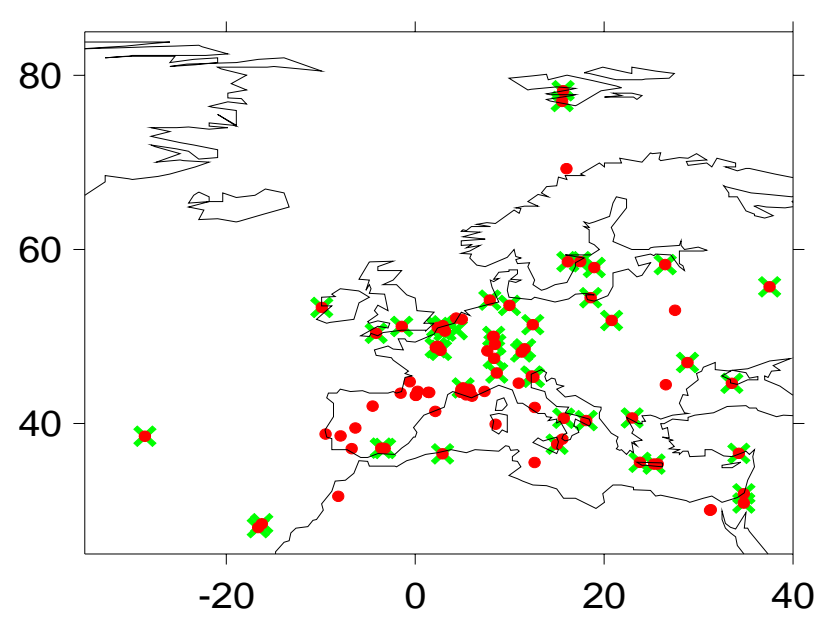

Fig. 1. Distribution of CIMEL sun/sky photometers in Europe and nearby areas. The sites, where the instrument has UV channels (340 and $380 \mathrm{~nm}$ ), are marked by green crosses.

dataset (collection 5) has a good quality over both land and ocean, except bright surfaces (snow and desert) and is available since 2000. For cloud filtering a standard MODIS cloud mask (MOD/MYD35) is used, which employs a series of visible and infrared threshold and consistency tests. Additional masking has been added, including an internal cloud mask based on spatial variability to identify low clouds and the reflectance in the $1.38 \mu \mathrm{m}$ channel to identify high clouds (http://modis-atmos.gsfc.nasa.gov/MOD35_L2/).

The AERONET/PHOTONS network (http://aeronet.gsfc. nasa.gov/) (Holben et al., 1998) has been in operation since the middle of 1990s and has quite satisfactory spatial coverage over Europe. Accurate multi-channel measurements by CIMEL sun/sky photometer through UV to near-infrared spectral region provide the data for evaluating a spectral dependence of aerosol optical thickness as well as many other inversion products including single scattering albedo and asymmetry factor (Dubovik and King, 2000). In addition, AERONET/PHOTONS measurements of aerosol optical thickness at $340 \mathrm{~nm}$ can be used for direct validation of the final aerosol product in UV spectral region.

Since both satellite and ground-based measurements refer to the middle 1990s - beginning of 2000s period, the influence of Pinatubo volcanic eruption on the increase of total aerosol loading can be neglected. At the same time, we should emphasize the existence of negative trends in aerosol optical thickness of about $-0.04-0.05$ per decade (at $500 \mathrm{~nm}$ ), which have been obtained over some areas in Europe (Ruckstuhl et al., 2008), and over the former Soviet Union since the 1980s (Gorbarenko et al., 2006; Makhotkina et al., 2005). Their nature is determined by both anthropogenic and natural processes and will not be discussed in this paper. However, one should take these trends into account while applying the results to another time period.

\section{Data and method description}

For estimating the aerosol impact on UV irradiance it is necessary to know several key aerosol characteristics: the aerosol optical thickness $\left(\tau_{\lambda}\right)$, the single scattering albedo $\left(\omega_{\lambda}\right)$, which characterizes the ratio of scattering to scattering plus absorption, and asymmetry factor $\left(\mathrm{g}_{\lambda}\right)$, which can be written in the form:

$\mathrm{g}_{\lambda}=\frac{\int_{-1}^{1} \cos \theta \cdot P(\theta) d(\cos \theta)}{\int_{-1}^{1} P(\theta) d(\cos \theta)}$

where $\theta$ is the scattering angle, $P(\theta)$ is the phase function.

Spectral dependence of aerosol optical thickness is usually defined by Angstrom parameter $\alpha$, which is estimated as follows:

$\alpha=-d \ln \left(\tau_{\lambda}\right) / d \ln (\lambda)$,

The monthly mean MODIS $\tau_{550}$ have been taken from http: //disc.sci.gsfc.nasa.gov/giovanni/ for the 2000-2008 period with $1^{\circ}$ spatial resolution over the area of $30-80^{\circ} \mathrm{N}, 28 \mathrm{~W}-$ $40^{\circ} \mathrm{E}$, which covers Europe and nearby territories. The measurements from both TERRA and AQUA satellite platforms were used to increase the statistics and to account possible aerosol changes during daytime.

The ground-based AERONET/PHOTONS quality assured measurements at level 2 (version 2) were used over the 19942006 period for evaluating the Angstrom parameter $\alpha$ to account spectral $\tau_{\lambda}$ dependence and for estimating the retrievals of single scattering albedo and asymmetry factor (Dubovik and King, 2000; Dubovik et al., 2002). Figure 1 presents the spatial distribution of Cimel sun/sky photometers, which data were used in the analysis. To exclude the systematical changes of aerosol parameters with surface elevation, only the data from the sites located lower than $1000 \mathrm{~m}$ were processed. Since overcast cloudy conditions prevent direct sun measurements, the total number of stations with available datasets varies from 73 in summer to 60 in winter. It should be mentioned that the number of Cimel sun/sky photometers with the UV channels is much smaller: the $\tau_{340}$ measurements are available from 39 sites in June-July and only from 31 in December (see Fig. 1).

Although the quality of MODIS data may be considered as satisfactory, several additional tests have been fulfilled. Figure 2 presents the difference in $\tau_{550}$ and in $\tau_{340}$ between satellite and ground-based datasets. The average uncertainty of monthly mean satellite $\tau_{550}$ retrievals lies within $\pm 0.02-$ 0.03 with small but statistically significant difference in the fall. However, the difference is not large and is much less than $\tau_{550}$ seasonal changes over all European regions. To get $\tau_{\lambda}$ estimates in the UV spectral range two approaches were used: by accounting for spectrally-dependent Angstrom parameter, which can be observed in some conditions (Eck et 

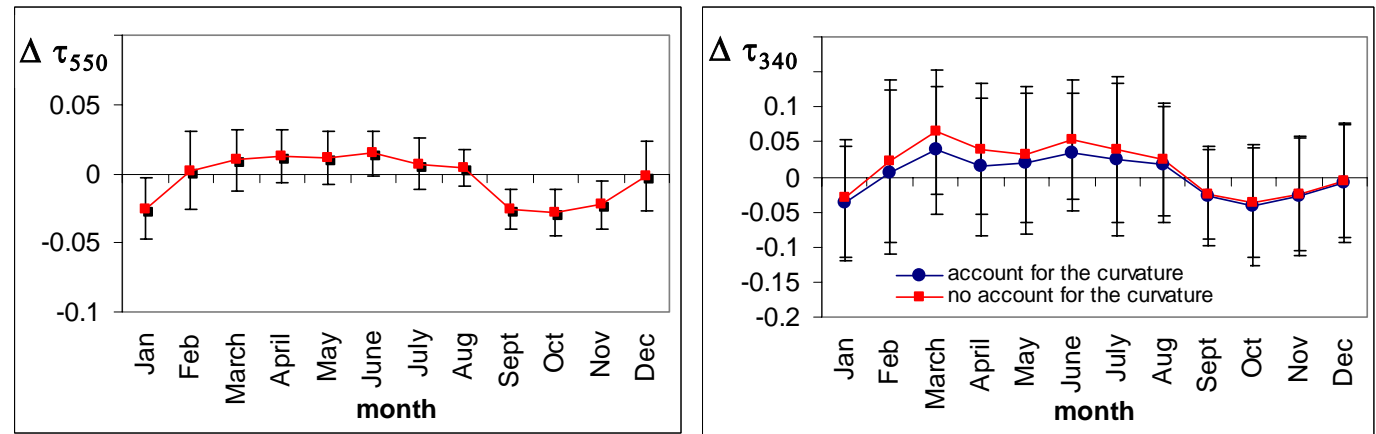

Fig. 2. The difference between MODIS and AERONET/PHOTONS aerosol optical thickness over Europe as a function of month at $550 \mathrm{~nm}$ (a) and at $340 \mathrm{~nm}$ (b). The confidence intervals were obtained at 95\% significant level. The difference with AERONET data at $340 \mathrm{~nm}$ is shown with the account and without account for spectral dependence of Angstrom parameter. See the details in the text.

al., 1999; Dubovik et al., 2002), and with the application of a constant $\alpha$ value retrieved from 440-870 nm spectral range. The comparisons between the $\tau_{340}$ estimated from MODIS data using both methods and direct ground $\tau_{340}$ CIMEL measurements have revealed the same character of the difference, though with higher deviation $( \pm 0.05)$ for the second one. The difference between the two methods is small and lies within $0.01-0.03$ that is close to the uncertainty of $\tau_{340}$ estimates. At the same time, due to the much smaller number of CIMEL instruments with UV channels (see Fig. 1) the advantages of accounting for spectral Angstrom curvature have been outweighed by the much lower statistics and, hence, larger uncertainty in the resulting Angstrom parameter spatial distribution. Finally, the application of the constant $\alpha_{440-870}$ values was chosen.

The additional analysis has revealed the presence of unrealistically high $\tau_{550}$ values (up to $\sim 0.7-0.8$ ) observed over some regions in the northern Arctic regions, probably, due to the existence of small spots of snow or ice within the pixel. Note, that according to the measurements at AERONET/PHOTONS sites located at high latitudes $\left(>58^{\circ} \mathrm{N}\right)$, the average $\tau_{550}$ values are about 0.1 with the maximum monthly mean value, not exceeding 0.2 . This threshold $\left(\tau_{550}=0.2\right)$ has been chosen as an additional filter, and has been applied to the MODIS data over the northern regions to remove unrealistically high $\tau_{550}$.

As a result, the $\tau_{550}$ climatology over Europe has been obtained (Fig. 3), which is used as a base for developing the UV aerosol climatology. Spatial distributions of Angstrom parameter $\alpha_{440-870}$ have been estimated using geostatistical ordinary Kriging method with a linear type of variogram model. The results are shown in Fig. 4. Using these distributions the final UV aerosol $\left(\tau_{340}\right)$ climatology has been generated (Fig. 5).

The final distributions of aerosol parameters over Europe are analyzed together with the spatial distribution of meteorological parameters. Near-surface wind speed is known to determine the source strength for several aerosols types (for example, sea salt, dust, primary organic particles) (IPCC, 2007). Wet removal of atmospheric aerosols is affected by precipitation, which can also change the soil moisture and vegetation, and, hence, generation of dust particles and biogenic emission. In order to qualify the possible reasons of aerosol optical thickness changes the data from IRI/LDEO Climate Data Library (http://iridl.ldeo.columbia.edu/) were used to produce maps over Europe with precipitation and wind fields at $925 \mathrm{hPa}$ for the period 1961-1990 on the base of NOAA NCEP CPC CAMS_OPI climatology (Janowiak and Xie, 1999; Kalnay et al., 1996). The monthly maps with meteorological fields are presented in Fig. 6.

\section{Results}

\subsection{Distribution of aerosol optical thickness and Angstrom parameter over Europe}

The monthly mean distributions of aerosol optical thickness and Angstrom parameter shown in Figs. 3-5 have some typical features in their seasonal and temporal variations. The changes in aerosol optical thickness have a tendency to increase towards the south-east, inward the continent, though with different gradients over the year. The $\tau_{340}$ values vary from $\sim 0.01$ over northern and north-western areas during cold period to $\tau_{340} \sim 0.9$ over the south, south-eastern regions during spring and summer. One should note very pronounced seasonal $\tau_{\lambda}$ changes, which are sometimes higher than their difference in space. The Angstrom parameter also increases towards the south-east and has noticeable seasonal changes with maximum in summer over continental area at the south-east and minimum over Atlantic ocean in winter. Figure 7 presents the examples of different seasonal $\tau_{340}$ distributions from both direct AERONET/PHOTONS measurements and the developed MODIS/AERONET climatology in the arctic (1), temperate (2), and subtropical (3) climate zones and several of their subtypes. The lowest $\tau_{\lambda}$ are observed in the arctic climate zone with the spring maximum 


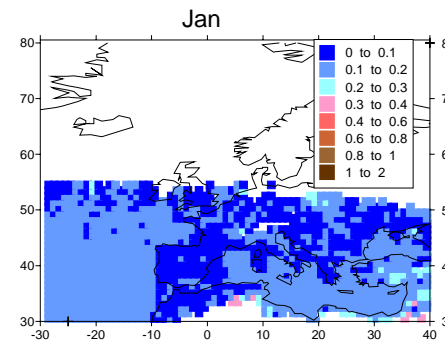

Feb

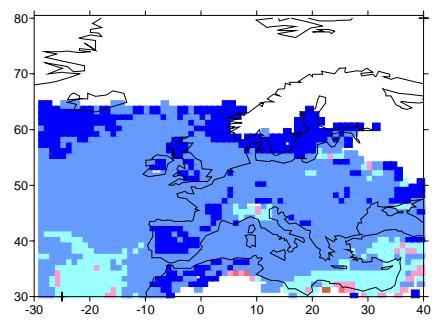

March

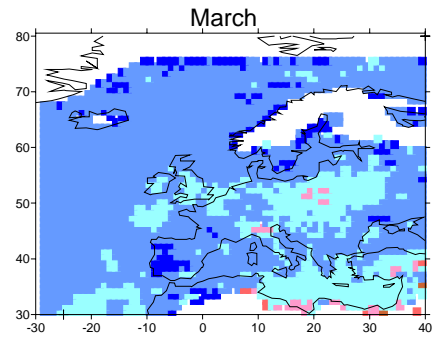

April

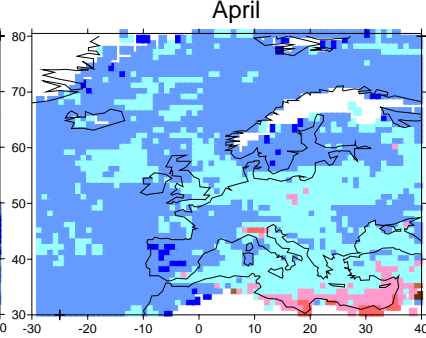

May
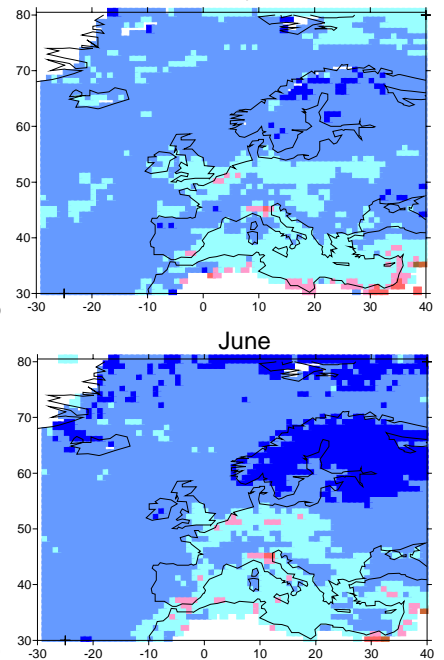

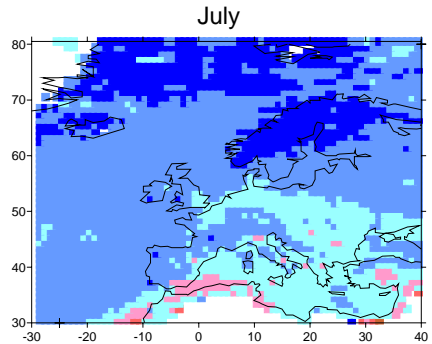

August

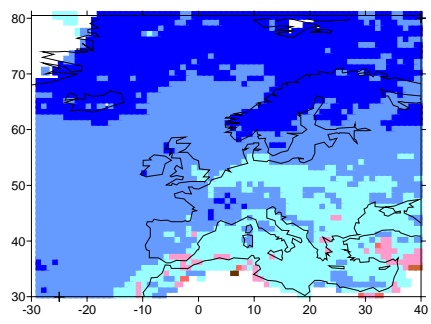

Sept

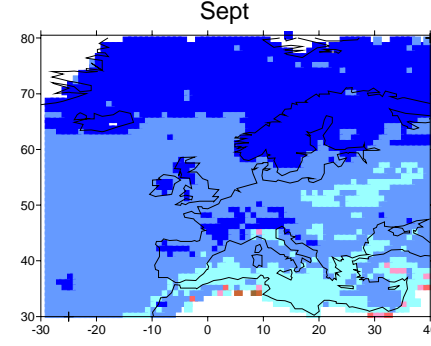

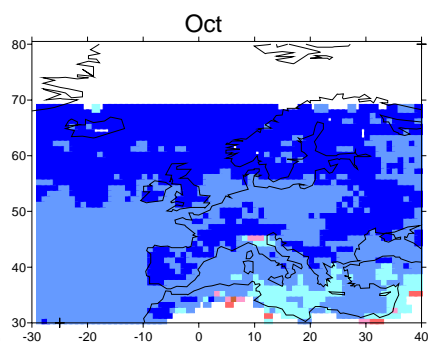

Nov

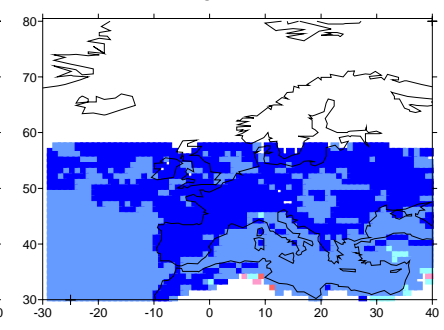

Dec

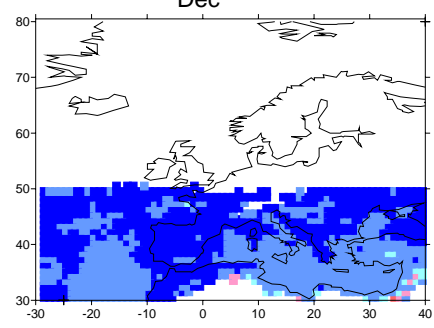

Fig. 3. Monthly spatial distribution of $\tau_{550}$ over Europe according to MODIS data with account of some corrections in high latitudes according to AERONET/PHOTONS dataset.

which, however, does not exceed $\tau_{340} \sim 0.23$. Within the temperate climate zone two subtypes can be found over Europe: the area with uniform humidification with one summer $\tau_{\lambda}$ maximum (the Oostende site) and the area transitional to continental type, located approximately eastward of $\sim 15^{\circ} \mathrm{E}$ and northward of $\sim 45^{\circ} \mathrm{N}$ with two $\tau_{\lambda}$ maxima in spring and summer like at Gotland, Toravere and Moscow sites. One can see much higher $\tau_{340}$ variations there with maxima reaching $\sim 0.4-0.5$. In the subtropical zone there is a distinct $\tau_{\lambda}$ increase towards inner continental areas from Spain to Greece with maxima observed during warm period. At the same time the characteristics of the changes in $\tau_{\lambda}$ are much more irregular over subtropics, which can be attributed to the effects of the mineral dust aerosol advection to different Mediterranean regions from the surrounding deserts. It is necessary to note, that at some sites (for example, in Thessaloniki) the long-term $\tau_{\lambda}$ dataset obtained from Brewer measurements provides much better agreement with MODIS data than that obtained between MODIS and AERONET dataset, possibly, due to larger statistics and the application of additional clear-sky filter (Kazadzis, 2007; Koukouli et al., 2007). (It should be noted that the data from the developed MODIS/AERONET climatology have been interpolated against the coordinates of the AERONET sites with one degree resolution dataset. Therefore, this picture should be considered not as the example of the validation but as a presentation of typical $\tau_{340}$ seasonal features in different areas of Europe obtained both from satellite and ground).

The analysis of monthly changes in Angstrom parameter over Europe, shown in Fig. 4, has revealed its substantial growth towards the inner continental regions during warm period with the high values $(\alpha>1.4)$ in June-July. This can be explained by relative decrease of sea salt aerosols and additional generation of fine mode particulate matter from different biogenic sources in conditions of high photolysis rates, elevated temperatures and increase of aerosol VOC precursors. During spring and summer one can see a substantial increase of $\alpha$ values even over the Atlantic area that can be explained, to some extent, by the formation of fine mode sulphate aerosol from photochemical reactions with dimethyl sulfide (DMS) from marine plankton (Andreae and Crutzen, 1997; Denman et al., 2007). Another source of fine-mode aerosol can be the advection of continental aerosol from the eastern coast of North America, which enhances both aerosol optical thickness and Angstrom parameter over Atlantic ocean. The back trajectory analysis described in (Smirnov et al., 2000) also confirmed that air originating above the continent was responsible for the increase in 

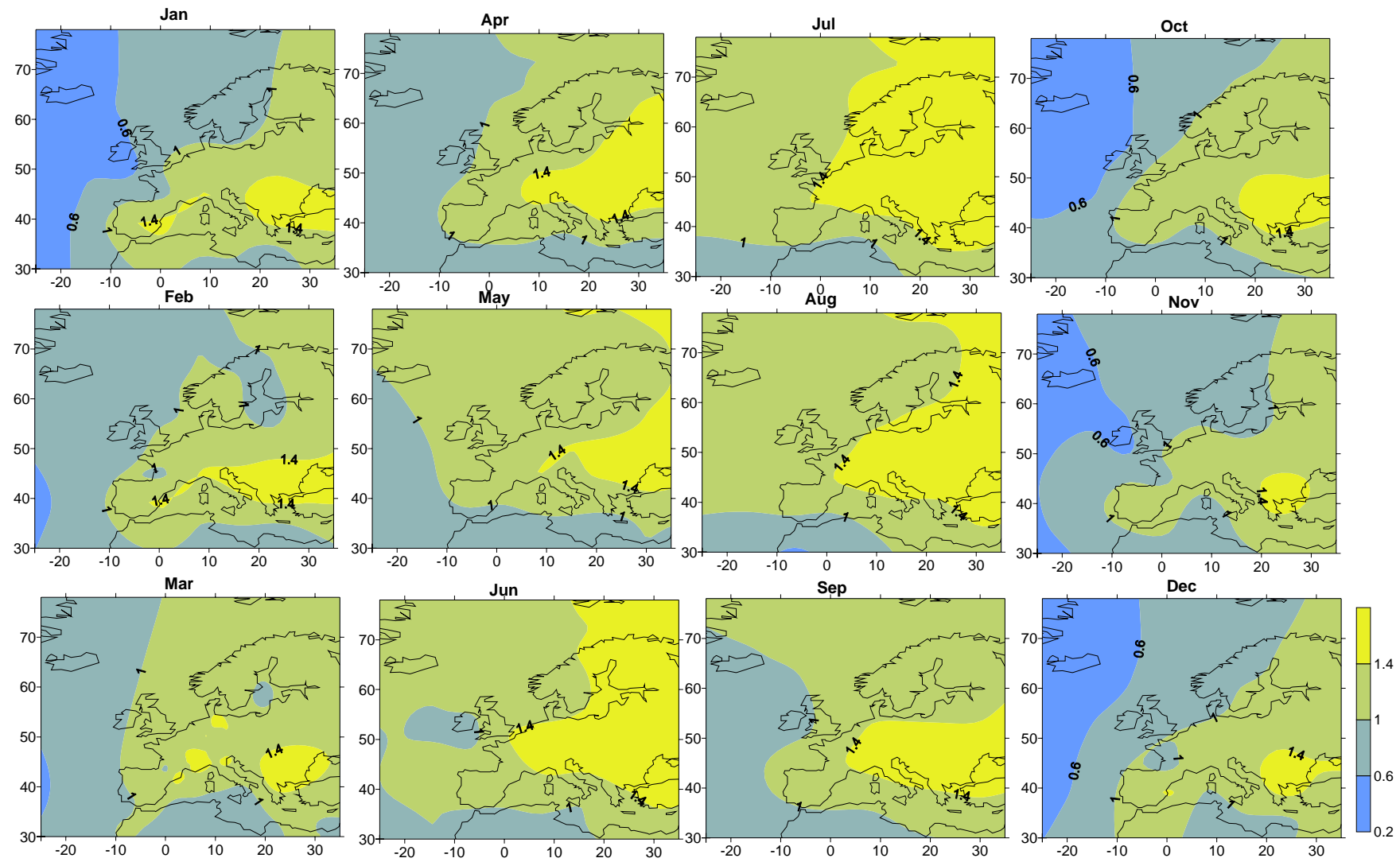

Fig. 4. Monthly spatial distribution of Angstrom parameter according to AERONET/PHOTONS dataset over Europe.

aerosol optical thickness and Angstrom parameter in remote Atlantic area during the TARFOX. In Smirnov et al. (2002) it was also mentioned the noticeable effects of different kinds of fine mode continental aerosol in Atlantic ocean. The increase of these aerosol parameters near the European coast can be also explained by the diffusion of polluted air directly from the European continent. All these assumptions should be studied further. During cold period the Angstrom parameter has a distinct decrease over almost the whole Europe due to significant enhancing of westerlies and precipitation (see Fig. 6), which result in the growth of the coarse mode sea salt aerosol concentration. However, even in cold period there is a tendency of increasing the fine mode aerosol towards inner continental regions at the south. A local $\alpha$ maximum at the south-eastern part of Europe over Balkan peninsula throughout the year can be explained by the joint effect of meteorological factors such as the lack of precipitation and attenuation in wet removal of aerosol, some specific features in air advection (see the discussion below).

Figure 5 demonstrates a permanent elevated aerosol loading due to pollution effects over several local areas: Northern Italy, the coast of the Netherlands, the southern regions of Poland, and, especially in summer, over the lowlands of the mid and low Danube areas. The qualitative analysis of distribution of fine mode particles $\mathrm{PM}_{2.5}$ obtained from chemical transport model LOTOS-EUROS (Schaap et al., 2007) for 2000 (see http://home.planet.nl/ $\sim$ scha1378/tno/ promote/) has also confirmed the existence of local maxima approximately over the same regions. The maximum monthly mean value can reach $\tau_{340} \sim 0.9\left(\tau_{550} \sim 0.45\right)$ over Northern Italy during spring-summer months, while $\tau_{340}$ is about $0.5\left(\tau_{550} \sim 0.25\right)$ over nearby unpolluted area. In other polluted regions the differences are not so large and are about $\Delta \tau_{340} \sim 0.05-0.2\left(\Delta \tau_{550} \sim 0.03-0.1\right)$. Direct comparisons of simultaneous measurements obtained by two collocated CIMEL sun/sky photometers in Moscow region (Meteorological Observatory of Moscow State University and Zvenigorod sites) have revealed an additional aerosol loading over Moscow megalopolis of about $\Delta \tau_{340} \sim 0.02-0.12$ $\left(\Delta \tau_{500} \sim 0.01-0.06\right)$ (Chubarova and Sviridenkov, 2008), which is in agreement with the MODIS estimates over the Moscow region. This analysis has also confirmed the ability of MODIS retrieval algorithm to produce high quality data and to reveal the areas with high local pollution. 

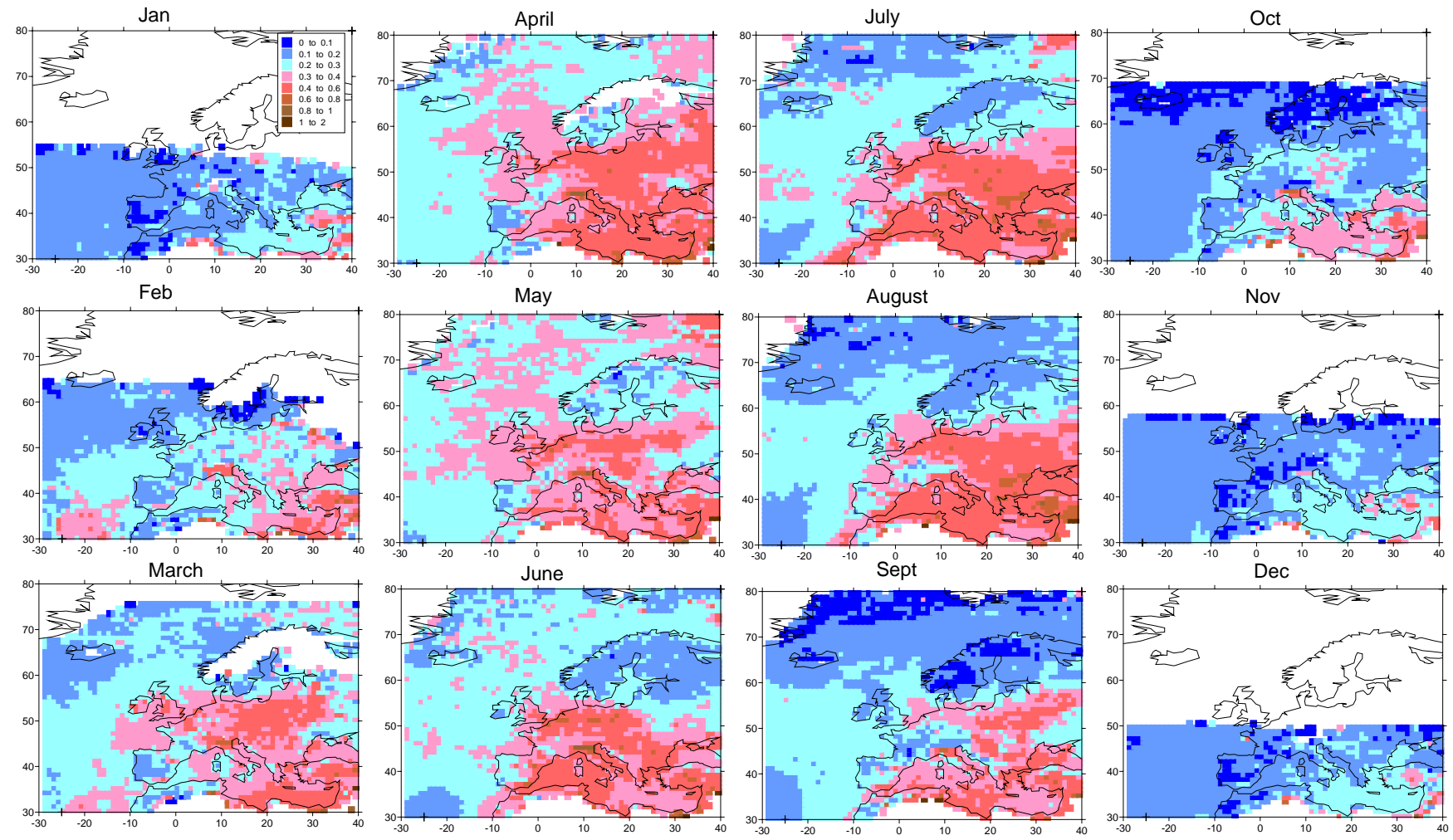

Fig. 5. Monthly spatial distribution of $\tau_{340}$ according to MODIS/AERONET data.

\subsection{Month-to-month variability of aerosol optical thickness and Angstrom parameter}

This section is devoted to the detailed analysis of month-tomonth variability of aerosol parameters together with the meteorological fields (see Figs. 3-6).

In January due to low temperatures and strong westerlies the $\tau_{\lambda}$ and $\alpha$ values are low all over Europe increasing towards the southeast. These south-eastern $\tau_{\lambda}$ and $\alpha$ maxima can be explained by additional advection of fine mode dust particles from Asia Minor (see Fig. 6), where the substantial amount of aerosol is observed. However, the $\tau_{\lambda}$ values there are not very high due to existing of snow cover (Myachkova, 1983), which prevents the formation of additional aerosol particles from ground. At the same time, there are pronounced local maxima over several industrial areas: south of Poland, western coast of Netherlands, Northern Italy. They are not very high $\left(\tau_{340} \sim 0.2-0.3, \tau_{550} \sim 0.1-0.2\right)$ but quite distinct. The difference with the nearby unpolluted regions comprises about $\Delta \tau_{340}=0.05-0.15\left(\Delta \tau_{550}=0.03-0.1\right)$. In February, there is an ubiquitous increase in the aerosol optical thickness over almost all Europe, except northern areas higher $58^{\circ} \mathrm{N}$. Central and Eastern Europe are located on the western periphery of Asian anticyclone. The $\tau_{\lambda}$ growth is associated with the precipitation decrease and with the weakening of circulation processes, which lead to additional accumulation of aerosol. In addition, one can see a pronounced $\tau_{\lambda}$ maximum over the Atlantic ocean near the coast of Africa and Spain, which can be attributed to the effects of dust aerosol advection from Sakhara desert. Comparatively high $\tau_{\lambda}$ values over the eastern Mediterranean area can be also explained by predominant advection of air mass from Africa and Arabian deserts with high aerosol loading. One can note the existence of the local $\tau_{\lambda}$ maxima over the same polluted regions which were observed in January. In March Eastern Europe is still located on the western periphery of Asian anticyclone with strong south-east winds from the steppe and desert areas, which are getting free from snow but still are not covered by grass (Myachkova, 1983) and therefore can be a substantial source of dust. The lack of precipitation to the east of $12-15^{\circ} \mathrm{E}$ creates favorable conditions for aerosol accumulation, and, hence, for the increase of the aerosol loading over this area, compared with that over Western Europe and, especially, over the Atlantic coast. However, one can see a slight reduce of aerosol loading over the regions located to the east of $30^{\circ} \mathrm{E}$ due to the presence of snow cover there. The local $\tau_{\lambda}$ maxima over the polluted areas described above are getting much more pronounced with $\tau_{340} \sim 0.6-0.8\left(\tau_{550} \sim 0.3-0.4\right)$. In April there is still the same type of atmospheric circulation over Eastern Europe with the domination of south-eastern winds from the steppe and desert 

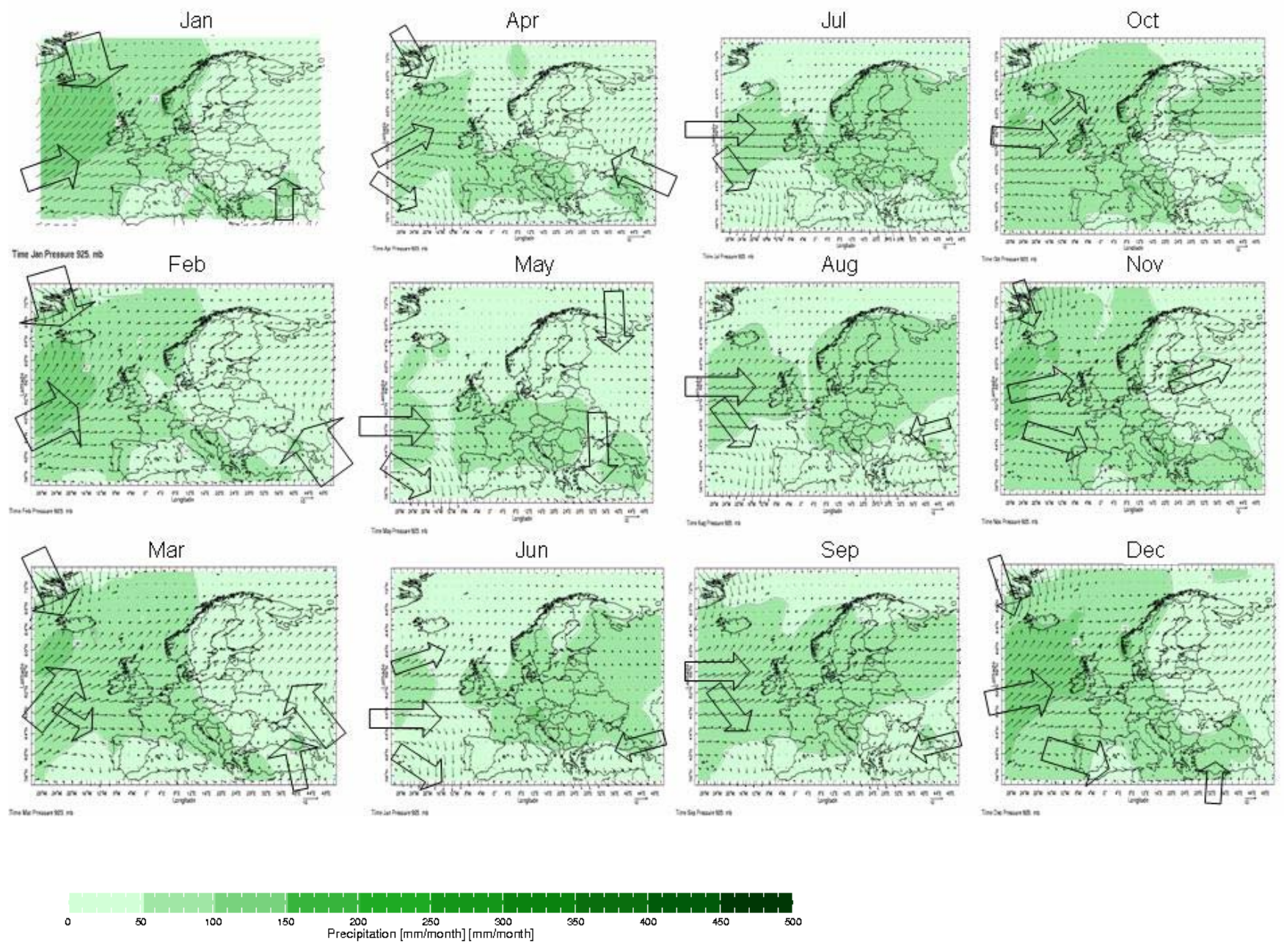

Fig. 6. Monthly spatial distribution of climate meteorological parameters (wind characteristics and precipitation) according to NCEP CPC CAMS_OPI data from the IRI/LDEO Climate Data Library, 1961-1990.

areas, which is characterized by the lack of precipitation. The beginning of agricultural activity, accompanied usually by the prescribed fires in the Eastern Europe, also creates additional source of fine-mode aerosol. Altogether these processes generate a distinct seasonal $\tau_{\lambda}$ maximum over Eastern Europe. One can also see an increase of the area with high Angstrom parameter $(\alpha>1.4)$ over the continental areas in Eastern and Central Europe. Low precipitation and the advection from Central European areas create favorable conditions to the accumulation of aerosol over Northern Europe and nearby North Sea area. The snow cover, which is still observed over this area, also reduces the uptake of aerosol by ground and contributes to the increase of the aerosol lifetime in the atmosphere, thus creating a seasonal maximum in aerosol optical thickness over Northern Europe. Western Europe is under the influence of the nearby Atlantic ocean, which is characterized by higher precipitation leading to active wet removal of aerosol. The location of the area with large precipitation over Western Europe is in a good agreement with the lower aerosol level with the approximate border at $10^{\circ} \mathrm{E}$. In May there are pronounced changes in the circulation processes over Europe with amplifying the Azore anticyclone and spreading its wedges over the Mediterranean area. This is accompanied by the decrease in precipitation over this area and, hence, by the accumulation of the aerosol particles. Over the northern areas one can see high aerosol loading due to the lack of precipitation and still snow surface. This April-May maximum in aerosol optical thickness agrees well with the results of long-term measurements of air transparency over Russian Arctic regions (Makhotkina et al., 2005). At the same time, the aerosol loading over Central and Eastern Europe reduces due to the increase in precipitation, the domination of northern air advection from Scandinavian regions and more intensive uptake of aerosol by grass and leaves. In June further increase of precipitation over the northern Eastern Europe and ceasing the air 
advection from the south are responsible for distinct local minimum in aerosol optical thickness over the vast territory to the north of $45^{\circ} \mathrm{N}$ and to the east of $15^{\circ} \mathrm{E}$. In addition, this local $\tau_{\lambda}$ minimum can be attributed to comparatively high water store in soil and vegetation, which can also prevent active mineral dust aerosol formation. At the same time, at the south and, especially, at the south-eastern areas (the eastern Mediterranean and western region of the Black sea) due to the lack of precipitation the processes of aerosol accumulation are observed. In addition, the air advection from the east (from Asia Minor) provides an additional mineral dust aerosol (see Fig. 6), that was also described in (Kazadsis et al., 2007). In addition, elevated temperatures and high photolysis rates in the presence of volatile organic precursors create favorable conditions for active generating there different kinds of fine mode biogenic and anthropogenic aerosols. We can see the increase in the area with fine mode particles over the whole Europe, except its western part and the shores of the Mediterranean Sea, where the influence of the coarse mode sea-salt and mineral dust aerosols from deserts are dominating. As a result, the yearly maximum of $\tau_{340} \sim 0.9$ ( $\tau_{550} \sim 0.4$ ), which is the highest value recorded over Europe, is observed over Northern Italy in June. In July aerosol optical thickness is very high over the Mediterranean area and nearby territories, especially over Balkan area: Northern Greece, Bulgaria, Romania (the lowlands of the mid and low Danube areas) which can be characterized by additional generation of aerosol particles from anthropogenic emissions in conditions of high photolysis rates and elevated temperatures in the absence of wet removal of aerosol from the atmosphere. The local aerosol maxima over the polluted areas mentioned above are also observed. Like in June, one can see a dominating role of fine mode particles over the whole Europe, except areas nearby the Atlantic Ocean and the Mediterranean Sea. In August the high aerosol loading over southern Europe is still observed due to the influence of the Azore anticyclone, which is characterized by hot and dry weather. At the same time, over the northern areas (higher $60^{\circ} \mathrm{N}$ ) one can see gradual decrease of aerosol optical thickness and Angstrom parameter. In summer, aerosol optical thickness undergoes the most strong spatial variability over Europe from the very low values over Skandinavia and Arctic ocean $\left(\tau_{340} \sim 0.1, \tau_{550} \sim 0.05\right)$ to the very high ones over the Mediterranean south-eastern area of Europe $\left(\tau_{340} \sim 0.7-0.9\right.$, $\tau_{550} \sim 0.3-0.4$ ).

In September lower temperatures and photolysis rates as well as the intensification of westerlies decrease the aerosol loading over the whole Europe area, except its south eastern part. The local maximum, which is observed over the central regions of Eastern Europe (Russia, Belarus, Poland, Moldova), has been generated due to the strong impact of extreme forest and peatbog fires observed in 2002 near Moscow (Chubarova et al., 2009). However, there is a high probability of such conditions due to the drainage of peatbogs and overall air temperature increase. In October further cleaning of the atmosphere is observed over the whole territory of Europe. This process is consistent with attenuation of the $\alpha$ values over the vast area with a distinct tendency to decreasing towards the Atlantic Ocean. There are still the centers over the south-eastern part of Europe with the high Angstrom parameter and the aerosol optical thickness. The location of the area with higher aerosol loading over central Europe (Czech Republic, Austria and nearby countries) corresponds well with the area with less precipitation. In November the aerosol optical thickness is quite low $\left(\tau_{340} \sim<0.2, \tau_{550}<0.12\right)$ over the whole European territory, except several local areas. The Angstrom parameter continues to decrease, that means further reduction of the area with the domination of the fine mode particles. Relatively high aerosol loading is observed over the Mediterranean area and, especially, over Northern Italy and the Balkan peninsula. The local area with high Angstrom parameter values $(\alpha>1.4)$ over the Balkan peninsula might be attributed to the joint effect of favorable conditions for generating the biogenic as well as anthropogenic aerosols from both natural and industrial emissions. In December the aerosol loading is the lowest in seasonal cycle due to the active removal of aerosol and the absence of its active generation in the atmosphere. However, the elevated aerosol optical thickness can be observed over several areas: the eastern part of the Mediterranean, which is under the influence of mineral dust advection from the deserts, over the lowlands of the mid and low Danube areas, over the industrial zones in Northern Italy, etc. The $\alpha$ values are also the lowest ones, and they are characterized by a pronounced increase towards the southeast. Unfortunately, it is impossible to retrieve the aerosol optical thickness over the large northern area due to bright snow conditions, where MODIS algorithm does not work properly. However, the data available from groundbased AERONET/PHOTONS network confirm the existence of low aerosol optical thickness over snow cover areas at the north.

Table 1 presents monthly mean and yearly mean $\tau_{340}$ over Europe averaged with $10 \times 10^{\circ}$ grid over $10^{\circ} \mathrm{W}-40^{\circ} \mathrm{E} 30^{\circ}-$ $80^{\circ} \mathrm{N}$ region. The data over Africa and Asia continents were excluded from the statistics. It summarizes the main features of seasonal behavior of aerosol optical thickness showed above.

It should be stated that the analysis of the aerosol sources and transport based on the wind and precipitation climatology can be considered as the first approach to explain the observed spatial distribution of aerosol optical thickness in Europe. The continuation of aerosol measurements together with model studies is necessary for better clarifying this issue.

\subsection{Aerosol single scattering albedo and factor of asymmetry}

Single scattering albedo and asymmetry factors are the important factors which is necessary to know for reliable 
Table 1. Monthly mean and yearly mean $\tau_{340}$ over Europe according to the developed MODIS/AERONET climatology averaged with $10 \times 10$ grid.

\begin{tabular}{|c|c|c|c|c|c|c|c|c|c|c|c|c|c|c|}
\hline longitude, ${ }^{\circ}$ & latitude, ${ }^{\circ}$ & 1 & 2 & 3 & 4 & 5 & 6 & 7 & 8 & 9 & 10 & 11 & 12 & Year \\
\hline-5 & 35 & 0.14 & 0.22 & 0.22 & 0.25 & 0.28 & 0.35 & 0.34 & 0.34 & 0.3 & 0.18 & 0.14 & 0.13 & 0.24 \\
\hline-5 & 45 & 0.14 & 0.21 & 0.28 & 0.28 & 0.31 & 0.31 & 0.32 & 0.3 & 0.23 & 0.19 & 0.13 & 0.14 & 0.24 \\
\hline-5 & 55 & 0.12 & 0.17 & 0.31 & 0.3 & 0.33 & 0.27 & 0.28 & 0.25 & 0.19 & 0.13 & 0.12 & 0.06 & 0.25 \\
\hline-5 & 65 & & 0.18 & 0.22 & 0.3 & 0.31 & 0.27 & 0.25 & 0.21 & 0.18 & 0.1 & & & \\
\hline-5 & 75 & & & 0.18 & 0.26 & 0.28 & 0.22 & 0.16 & 0.14 & 0.1 & & & & \\
\hline 5 & 35 & 0.17 & 0.26 & 0.28 & 0.38 & 0.37 & 0.43 & 0.47 & 0.43 & 0.37 & 0.28 & 0.2 & 0.18 & 0.32 \\
\hline 5 & 45 & 0.16 & 0.25 & 0.32 & 0.34 & 0.35 & 0.41 & 0.38 & 0.33 & 0.24 & 0.21 & 0.13 & 0.13 & 0.27 \\
\hline 5 & 55 & 0.16 & 0.21 & 0.32 & 0.37 & 0.35 & 0.36 & 0.36 & 0.35 & 0.27 & 0.18 & 0.15 & & \\
\hline 5 & 65 & & 0.12 & 0.2 & 0.29 & 0.28 & 0.23 & 0.23 & 0.21 & 0.16 & 0.1 & & & \\
\hline 5 & 75 & & & 0.2 & 0.26 & 0.3 & 0.24 & 0.17 & 0.14 & 0.11 & & & & \\
\hline 15 & 35 & 0.2 & 0.29 & 0.34 & 0.41 & 0.39 & 0.41 & 0.45 & 0.47 & 0.39 & 0.32 & 0.24 & 0.2 & 0.34 \\
\hline 15 & 45 & 0.17 & 0.28 & 0.38 & 0.45 & 0.4 & 0.46 & 0.45 & 0.43 & 0.31 & 0.25 & 0.19 & 0.17 & 0.34 \\
\hline 15 & 55 & 0.18 & 0.18 & 0.33 & 0.39 & 0.35 & 0.35 & 0.38 & 0.37 & 0.27 & 0.2 & 0.14 & & \\
\hline 15 & 65 & & 0.09 & 0.18 & 0.24 & 0.23 & 0.17 & 0.17 & 0.15 & 0.11 & 0.09 & & & \\
\hline 15 & 75 & & & 0.22 & 0.25 & 0.27 & 0.23 & 0.18 & 0.15 & 0.12 & & & & \\
\hline 25 & 35 & 0.2 & 0.31 & 0.39 & 0.45 & 0.38 & 0.4 & 0.47 & 0.46 & 0.4 & 0.34 & 0.26 & 0.21 & 0.36 \\
\hline 25 & 45 & 0.18 & 0.28 & 0.37 & 0.42 & 0.34 & 0.43 & 0.53 & 0.51 & 0.36 & 0.21 & 0.18 & 0.16 & 0.33 \\
\hline 25 & 55 & 0.24 & 0.24 & 0.37 & 0.43 & 0.35 & 0.24 & 0.37 & 0.37 & 0.33 & 0.18 & 0.14 & & \\
\hline 25 & 65 & & 0.1 & 0.22 & 0.33 & 0.22 & 0.16 & 0.2 & 0.17 & 0.13 & 0.1 & & & \\
\hline 25 & 75 & & & 0.24 & 0.28 & 0.33 & 0.21 & 0.2 & 0.16 & 0.12 & & & & \\
\hline 35 & 45 & 0.19 & 0.27 & 0.3 & 0.41 & 0.31 & 0.37 & 0.47 & 0.47 & 0.32 & 0.24 & 0.2 & 0.16 & 0.31 \\
\hline 35 & 55 & 0.2 & 0.31 & 0.31 & 0.43 & 0.33 & 0.24 & 0.37 & 0.37 & 0.35 & 0.18 & 0.13 & & \\
\hline 35 & 65 & & 0.04 & 0.21 & 0.35 & 0.27 & 0.17 & 0.25 & 0.21 & 0.16 & 0.16 & & & \\
\hline 35 & 75 & & & 0.28 & 0.32 & 0.34 & 0.24 & 0.3 & 0.19 & 0.13 & & & & \\
\hline
\end{tabular}

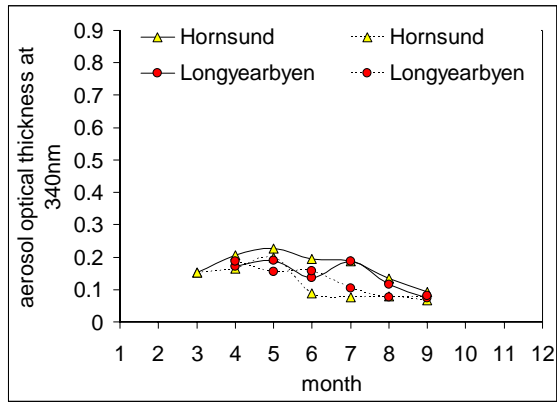

(1)

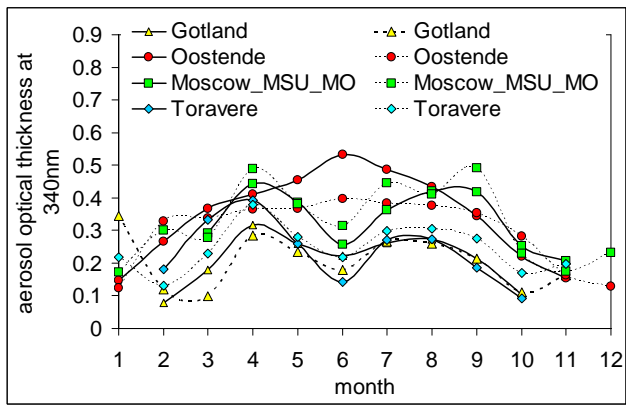

(2)

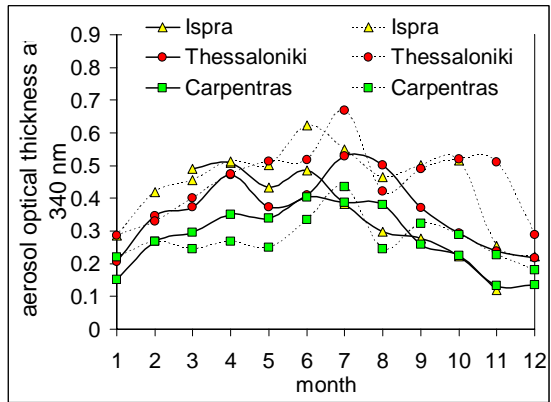

(3)

Fig. 7. Seasonal differences $\tau_{340}$ in the arctic (1), temperate (2) and subtropical (3) climate zones. The MODIS $\tau_{340}$ retrievals are shown by solid lines and AERONET/PHOTONS data - by dotted lines. The coordinates of the sites: Hornsund $\left(15.55^{\circ} \mathrm{E}, 77^{\circ} \mathrm{N}\right)$, Longyearbyen $\left(15.649^{\circ} \mathrm{E} 78.2^{\circ} \mathrm{N}\right)$, Gotland $\left(19.0^{\circ} \mathrm{E} 57.9^{\circ} \mathrm{N}\right)$, Moscow_MSU_MO $\left(37.5^{\circ} \mathrm{E}, 55.7^{\circ} \mathrm{N}\right)$, Oostende $\left(2.9^{\circ} \mathrm{E} 51.2^{\circ} \mathrm{N}\right)$, Toravere $\left(26.5^{\circ} \mathrm{E}\right.$, $\left.58.3^{\circ} \mathrm{N}\right)$, Ispra $\left(8.6^{\circ} \mathrm{E}, 45.8^{\circ} \mathrm{N}\right)$, Carpentras $\left(5.1^{\circ} \mathrm{E}, 44.1^{\circ} \mathrm{N}\right)$, Thessaloniki $\left(23.0^{\circ} \mathrm{N}, 40.6^{\circ} \mathrm{E}\right)$.

UV estimates in the aerosol atmosphere. In our approach they were retrieved through the special inversion algorithm (Dubovik et al., 2000) developed for sun/sky CIMEL photometers AERONET network. However, the method has some constraints. The most important ones are the existence of clear sky conditions during a series of observations and high aerosol loading $\left(\tau_{440}>0.4\right)$. As a result, during cold period over for the most of European territory there are no estimates of single scattering albedo due to low aerosol optical thickness and dominating of cloudy conditions. The $\omega_{\lambda}$ estimates are available only from few sites over southern regions (for example, only from 4 sites in December). Even 


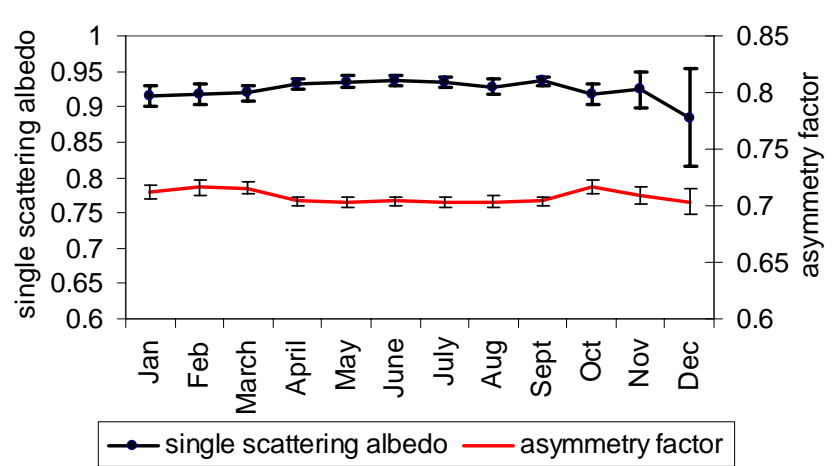

Fig. 8. Month-to-month variations of single scattering albedo $\left(\omega_{440}\right)$ and asymmetry factor $\left(\mathrm{g}_{440}\right)$ according to CIMEL sun/sky photometer measurements over Europe. The confidence intervals are shown at $95 \%$ level.

in summer the statistics is quite poor: the data are available from approximately 40-50 sites, which monthly average values can be based sometimes only on 1-2 observations per month. The lack of statistics and the uncertainty of the $\omega_{\lambda}$ retrievals $(\Delta \omega= \pm 0.03)$ do not allow us to generate spatial distributions of these parameters. Instead, a study of their month-to-month variability has been conducted. The month-to-month variations of both single scattering albedo and factor of asymmetry at $440 \mathrm{~nm}$ retrieved, using a standard AERONET algorithm, are shown in Fig. 8. No seasonal change in these characteristics could be detected at the $95 \%$ confidence level, except some small difference (about 0.01) in asymmetry factor values, which are higher in February, March and October. However, the difference is rather small and can be of random character that should be studied further. It should be emphasized that the absence of seasonal variations in single scattering albedo, which has been obtained, corresponds to the situations with high aerosol loading, that is the constraint for the $\omega$ retrieval procedure. At the same time, it is high aerosol loading that influences significantly the solar irradiance reaching the surface, while solar irradiance is not so sensitive to the changes in $\omega$ at small aerosol optical thickness. Therefore, these retrievals can be chosen in the first approach for estimating UV irradiance in Europe. As a result, yearly mean single scattering albedo at $440 \mathrm{~nm}$ over European region is about $\omega_{440}=0.93$ with standard deviation of 0.03 varying from 0.77 to 0.99 . Asymmetry factor comprises $\mathrm{g}_{440}=0.71$ with standard deviation of 0.02 varying from 0.58 to 0.79 .

Then, it was necessary to make spectral adjustments and to re-evaluate single scattering albedo and asymmetry factor in UV range. This has been made with the application of Mie theory with accounting for the characteristics of volume particle size distribution and refractive indices at $440 \mathrm{~nm}$, which in turn are the standard products of AERONET CIMEL sun/sky photometer network. The assumption of the same values of refractive indices in visible and UV spectra will not work properly in some cases, especially in smoke aerosol conditions (Chubarova et al., 2009). However, we can use this approximate approach due to the large statistics and the low frequency of fire smoke conditions in the overall dataset. As a result, the adjustment factors of $\Delta \omega \sim 0.01$ and of $\Delta \mathrm{g} \sim 0.04$ have been obtained to provide the average estimates of $\omega \sim 0.94$ and of $g \sim 0.75$ in the UV region of the spectrum. These values were taken as constants within the whole UV range. In order to obtain more accurate retrievals of these aerosol parameters one should use additional spectral or UV-MFRSR measurements and follow more sophisticated methods described, for example, in (Bais et al., 2005; Krotkov et al., 2005). Unfortunately, at present there is no spread network of these measurements to give good spatial distribution of these parameters.

\subsection{Validation against measurements}

The examination of the proposed method for evaluation the UV single scattering albedo and factor of asymmetry has been made by comparing model UV estimates with the experimental data in clear sky conditions with different aerosol properties in Moscow. For this purpose a Troposphere Ultraviolet and Visible (TUV) radiative transfer model version 4.1 has been used (Madronich and Flocke, 1998) with 8 stream DISORT solver and pseudo spherical corrections.

The measurements of erythemally weighted irradiance $\left(Q_{e}\right)$ in Moscow State University Meteorological Observatory are being carried out by broadband YES UVB-1 pyranometer (Chubarova, 2008). The instrument is regularly tested against the reference instrument, which in turn is regularly calibrated in erythemally-weighted units against the ultraviolet spectroradiometer Bentham DTM-300 of the Medical University of Innsbruck in 1999, 2005, 2008 (courtesy of M. Blumthaler). The additional corrections on solar zenith angle and ozone content are applied following the WMO recommendations (Seckmeyer et al., 2006) and cosine characteristics of the instrument have been also taken into account. The clear sky conditions were chosen from hourly visual observations. In addition, the account of typical $\mathrm{NO}_{2}$ gas absorption, which is the most important absorber in Moscow conditions, has been considered in model calculations according to the available surface $\mathrm{NO}_{2}$ measurements combined with its model profile.

The comparisons of model and measured $Q_{e}$ at low aerosol optical thickness $\left(\tau_{340}<0.1\right)$, where the effects of uncertainty in single scattering albedo and factor of asymmetry are negligible, has revealed the existence of some model overestimation of about $6 \%$. After taking this shift into consideration, we estimated the $Q_{e}$ loss due to aerosol $\left.\mathrm{L}=\left(Q_{e \_ \text {aerosol}}-Q_{e \_ \text {no_aerosol }}\right) / Q_{e \_ \text {no_aerosol }}\right)$, where the $Q_{e_{-} \text {aerosol }}$ values were taken both from the results of modelling and observations. The comparison between observed and modelled $\mathrm{L}$ values is shown in Fig. 9a for a wide range of aerosol optical thickness $\left(\tau_{340}=0.53 \div 1.7\right)$, and single 


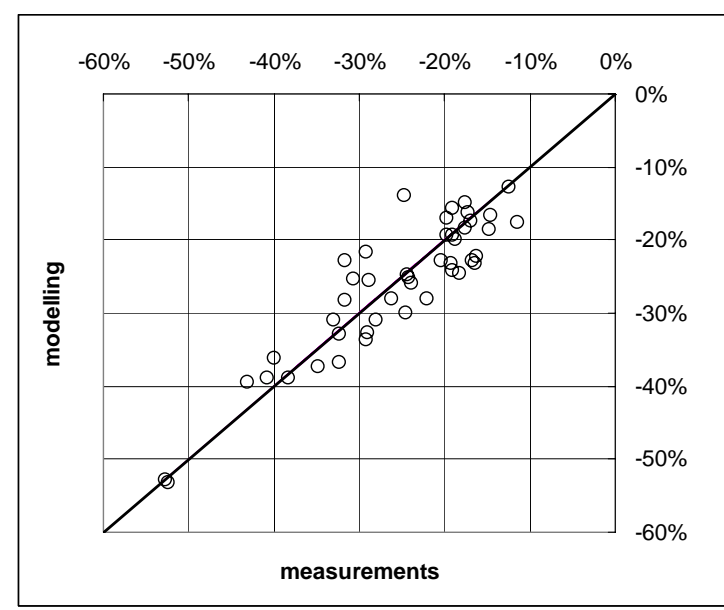

$\mathrm{a} /$.

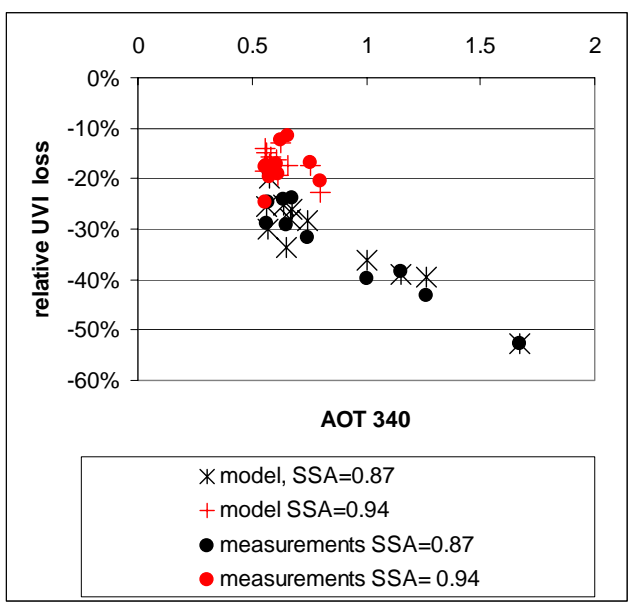

b/.

Fig. 9. The comparison between model and measured erythemally-weighted irradiance losses in clear sky conditions with the values of single scattering albedo and factor of asymmetry derived from the AERONET dataset (a) and relative UV loss as a function of aerosol optical thickness at $340 \mathrm{~nm}$ (b). Moscow. Snow-free conditions.

scattering albedo $(\omega=0.8 \div 0.97)$ obtained from AERONET measurements according to the approach described above. One can see quite satisfactory agreement between modelled and measured $Q_{e}$ aerosol loss with correlation coefficient $r=0.91$. Even in typical, non-smoke conditions the attenuation by aerosol can be very significant and exceed $50 \%$ due to comparatively small $\omega$ values and the episodes with high AOT loading. The effects of aerosol on UV attenuation based on spectral measurements as well as model simulations have been discussed in many papers (see, for example, Arola et al., 2003; Badosa et al., 2007; Balis et al., 2004; Früh et al., 2003; Jaroslawski and Krzy'scin, 2005; Krotkov et al., 2005 , etc.). For most cases the agreement between model and observed values lies within $10 \%$. This uncertainty can be observed due to non accounting in simulations for some aerosol properties, and due to possible effects of gas absorption. However, aerosol optical thickness and single scattering albedo remain the most important characteristics, which knowledge is essential for UV retrievals.

In addition, using model calculations a simple equation can been obtained to quantify the dependence of relative $Q_{e}$ loss on aerosol optical thickness (for $\tau_{340}<0.8$ ), single scattering albedo (for $\omega \geq 0.8$ ), and airmass (for $m \leq 2$ ):

$$
\begin{aligned}
& \frac{\Delta Q_{e}}{Q_{e}}=\tau_{340}[(0.42 m+0.93) \omega+(-0.49 m-0.97)] \\
& R^{2}=0.99
\end{aligned}
$$

The equation in the brackets is the attenuation coefficient, which characterizes the attenuation at $\tau_{340}=1$ and is a function of airmass $m$ and single scattering albedo $\omega$. For typical European summer conditions with $\omega \sim 0.94$ and at $m=1.2$, and $\tau_{340}=0.4$ this attenuation is about -0.08 . The uncertainty of this equation is less than $1 \%$, except the cases with high aerosol loading and low single scattering albedo, when the uncertainty can reach $2-3 \%$.

Our estimations have shown that the changes in asymmetry factor within $\pm 2 \sigma$ lead to less than $\pm 1 \%$ variations in erythemally-weighted irradiance. Therefore it is possible not to use it as an independent parameter in the Eq. (3).

The effects of single scattering albedo on UV attenuation can be quite pronounced. Unfortunately, due to the lack of statistics it is impossible to generate the maps with spatial distribution of this characteristic. However, we evaluated the range of UV relative changes due to $\pm 2 \sigma$ variations in single scattering albedo observed over Europe. The estimations were fulfilled for aerosol optical thickness averaged over $10 \times 10^{\circ}$ from Table 1 using the Eq. (3). As a result, mean uncertainty in $Q_{e}$ attenuation due to single scattering albedo is about $5 \%$ varying from 2 to $8 \%$.

Figure $9 \mathrm{~b}$ presents the dependence of relative $Q_{e}$ loss on aerosol optical thickness. The data were combined into two groups with different $\omega$ values in order to test the ability of the proposed method to reveal the effects of single scattering albedo. One can see quite pronounced distinction due to different $\omega$ in both observed and modelled $L$ values and a good agreement between their values. In conditions with relatively high single scattering albedo $(\omega \sim 0.94)$ the $Q_{e}$ aerosol loss is typically less than $20 \%$, while at $\omega \sim 0.87$ it comprises about $25-30 \%$ at the same aerosol optical thickness. Thus, the AERONET inversion products with some adjustments can be used for the assessment of aerosol properties in UV range. 


\subsection{UV changes due to aerosol}

The TUV model has been also applied for estimating the $Q_{e}$ aerosol loss over Europe. Model simulations were fulfilled for noon conditions (minimum solar zenith angle) in aerosol and in aerosol free situations. In addition, seasonal and spatial changes in total ozone content retrieved from TOMS ozone climatology dataset (http://jwocky.gsfc.nasa. gov/) have been also accounted.

Both relative and absolute changes of UV irradiance due to aerosol have been evaluated for central months of the seasons. The absolute changes due to aerosol are shown in UV indices $(U V I)$, which are defined by simple multiplying the $Q_{e}\left(\mathrm{~W} / \mathrm{m}^{2}\right)$ by 40 (Vanicek et al., 2000). Figure 10a presents a significant variation of monthly mean $Q_{e}$ relative losses over Europe due to aerosol loading, which lie within $\sim-1--17 \%$. Here, the $Q_{e}$ attenuation is mainly regulated by aerosol optical thickness and has a small negative dependence on airmass $m$ (see the Eq. 3). As a result, the most significant $Q_{e}$ loss of about $-15-17 \%$ was estimated over Northern Italy in spring and in autumn due to high aerosol loading and lower solar elevations compared with summer conditions. The minimum $Q_{e}$ attenuation $(>-3 \%)$ is observed over the North Atlantic ocean, Scandinavia in autumn and in winter, where the aerosol loading is small $\left(\tau_{340} \sim 0.1\right)$ and over some other clean regions like, for example, western coast of Spain in January. On average, there is a tendency of increasing the $Q_{e}$ loss towards inner continental regions, especially during warm period.

In winter, in spite of relatively small aerosol optical thickness, the $Q_{e}$ attenuation over Europe is quite pronounced varying within $-3--10 \%$ and increases on $3-5 \%$ over urban polluted areas (i.e. the coast of Netherlands, south of Poland) and towards the south. It is necessary to note that due to relatively higher solar elevation over the Mediterranean area, compared with North Europe, the loss of $Q_{e}$ over the polluted Northern Italy is not so large. In spring, due to the increase in aerosol loading one can see the enhancement of $Q_{e}$ loss over the whole Europe. The attenuation of $Q_{e}$ varies within $-5-15 \%$ with a pronounced drop up to $-15 \%$ over Central, Eastern and North-Eastern Europe. The distinct shifting of high $Q_{e}$ loss to the north in spring, where the aerosol optical thickness is not so high, is also attributed to smaller solar elevations there. In summer, the maximum loss in $Q_{e}$ reaching $-10--15 \%$ is observed at the southern and south-eastern European areas including several local polluted regions like over the lowlands of the mid and low Danube areas, Northern Italy, south of Poland, etc. In autumn, there is a pronounced decrease of $Q_{e}$ loss over the whole European territory, and, especially over the north Atlantic area, except several polluted areas and, especially, Northern Italy.

Figure $10 \mathrm{~b}$ represents the spatial distribution of absolute reduction in monthly mean $U V$ indices $(\Delta \mathrm{UVI})$ due to aerosol over Europe. Since absolute UVI loss has a positive correlation with both aerosol optical thickness and solar elevation, one can see a different picture. Over the southern regions with high aerosol loading the $\Delta \mathrm{UVI}$ is enhanced, while over northern areas, especially in winter, it is quite negligible in spite of their relative significant loss. As a result, in winter a typical absolute decrease of UV indices due to aerosol varies from less than $\Delta \mathrm{UVI} \sim-0.1$ over northern and central European territory to $\Delta \mathrm{UVI} \sim-0.3$ over southern regions. However, significant changes in aerosol loading can provide large variations in $U V I$. For example, at the same latitude $\left(\sim 40^{\circ} \mathrm{N}\right)$ in spring the absolute $U V I$ difference varies within the order of magnitude (from -0.1 to -1.0 ). In summer the absolute $U V I$ loss can exceed -1.0 over the southeastern areas, where the aerosol loading is extremely high. The maximum effect of aerosol is observed over Northern Italy, where the difference in UV indices due to aerosol loading can reach 1.5. At high latitudes, where the absolute level of UV irradiance is not so high, the absolute changes in $U V I$ also do not exceed 0.5. In autumn one can see typical decrease of less than 0.5 over the whole Europe, except Northern Italy, where aerosol optical thickness is still high.

\section{Discussions and conclusions}

In the paper we have shown that the combined MODIS/AERONET datasets can be used for the development of the UV aerosol climatology over Europe. The comparisons with direct ground-based CIMEL measurements at $340 \mathrm{~nm}$ have revealed the uncertainty of $\Delta \tau_{340}= \pm 0.05$, which is much less than the seasonal $\tau_{340}$ variations over the most territory of Europe. (It should be noted that the same approach has been used for evaluating the aerosol optical thickness climatology at $308 \mathrm{~nm}$ over Europe within the frame of the COST726 project. The dataset can be found at the site www.cost726.org).

The analysis of aerosol optical thickness and Angstrom parameter spatial distribution over Europe has been carried out together with the analysis of meteorological fields, which have revealed several interesting features in seasonal and spatial distribution:

1. Increasing of the aerosol optical thickness from the north-west towards south-east is observed with $\tau_{\lambda}$ maxima during warm period. The existence of spring aerosol maximum over northern arctic areas has been confirmed. Summer $\tau_{\lambda}$ maximum is typical for the western coastal zone of Europe as well as over the south and south-east European areas which, however, is much stronger. The bimodal seasonal distribution in aerosol optical thickness with spring and summer maxima and the pronounced drop of $\tau_{\lambda}$ in June refers to the large continental area to the north of $\sim 45^{\circ} \mathrm{N}$ and to the east of $\sim 15^{\circ} \mathrm{E}$. Most clean areas with $\tau_{340}$ less than 0.1 are observed during cold period over north-western part of the Atlantic ocean, over Scandinavia, and some other 
a.

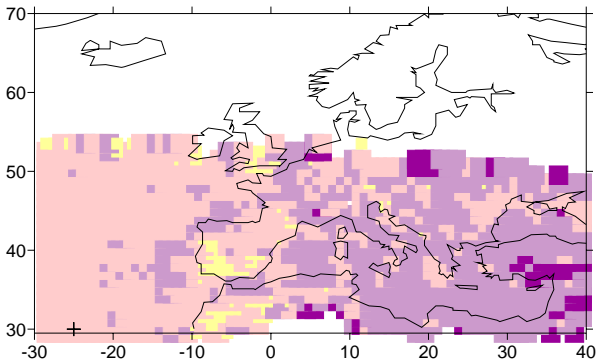

b.

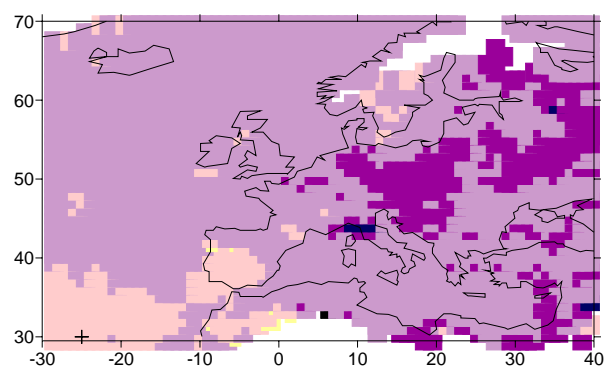

c.

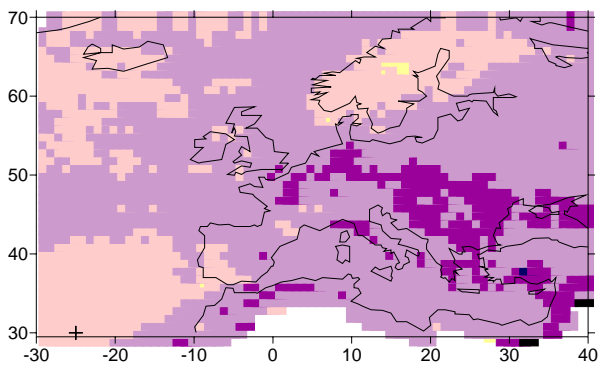

d.

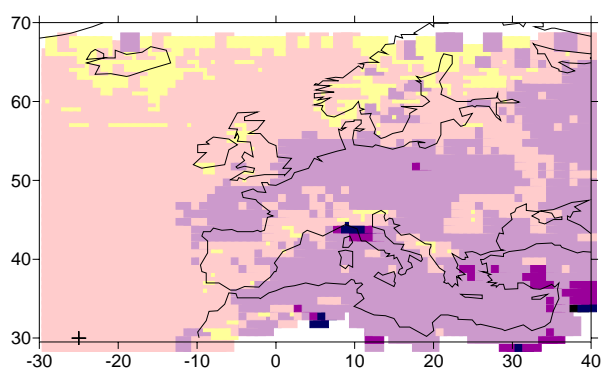

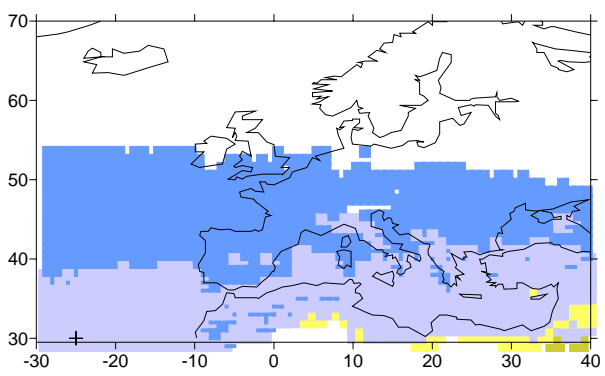
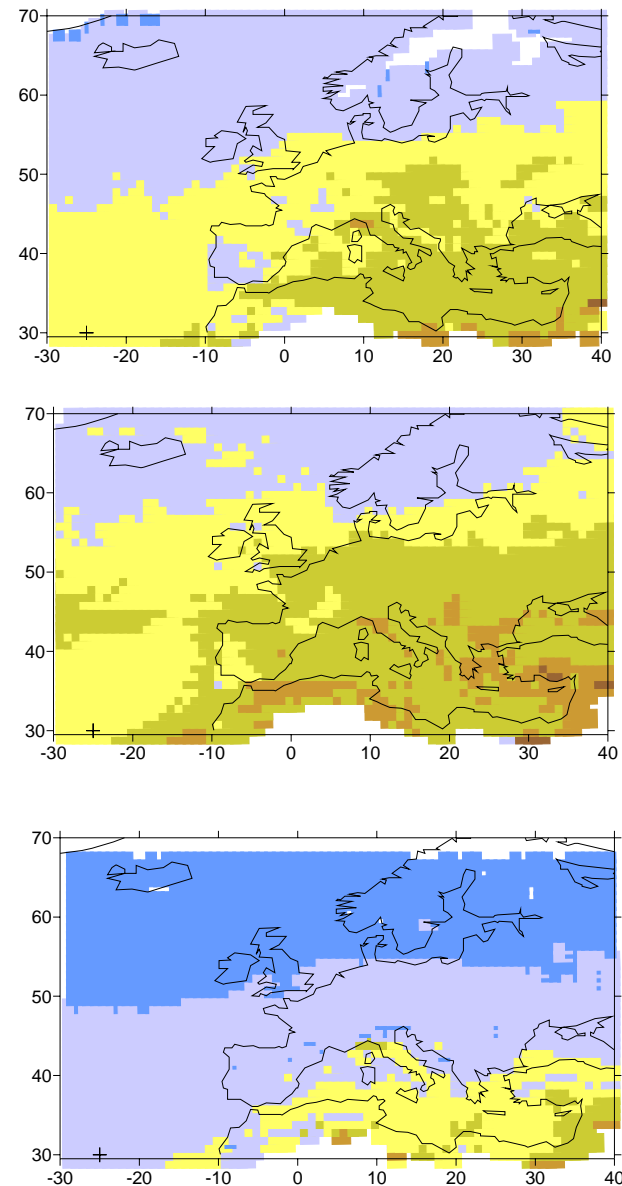

\section{Legends:}

\begin{tabular}{|l}
$\square-25$ to -20 \\
-20 to -15 \\
-15 to -10 \\
-10 to -5 \\
-5 to -3 \\
-3 to 0
\end{tabular}

-2 to -1.5

-1.5 to -1

-1 to -0.5

-0.5 to -0.3

-0.3 to -0.1

-0.1 to 0

Fig. 10. Relative (in percent) attenuation (left) and absolute (dimensionless) reduction (right) of UV indices ( $\Delta$ UVI) due to aerosol in January (a), April (b), July (c) and October (d) over Europe. Noon conditions.

local areas. The highest monthly mean aerosol optical thickness values (up to $\tau_{340} \sim 0.9$ ) have been obtained during warm period over several local areas mostly at the southern, south-eastern part of Europe.
2. There are noticeable seasonal changes in Angstrom parameter, which are characterized by its increase in summer, even over the Atlantic Ocean with a permanent local maximum over south-eastern part of Europe. These 
features can be explained by joint effects of air advection, lack of precipitation and vegetation activity, which determines the photochemical generation of different types of fine mode aerosol.

3. There have been revealed several local polluted centers with elevated aerosol optical thickness. The most significant ones are located in Northern Italy, over the coast of the Netherlands, the southern regions of Poland (carboniferous basin, and different industries), and, in summer, over the lowlands of the mid and low Danube areas. These areas are consistent with the areas with high concentration of $\mathrm{PM}_{2.5}$ particles obtained from chemical transport model LOTOS-EUROS.

The average estimates of single scattering albedo and asymmetry factor $(\omega \sim 0.94, \mathrm{~g} \sim 0.75)$ have been obtained in UV spectral region on the base on AERONET/PHOTONS retrievals. No seasonal dependence has been revealed for these parameters. However, it should take into account the constraints of the inversion method, which can be only applied for large $\tau_{\lambda}$.

Satisfactory agreement between UV measurements and model estimates in conditions with different aerosol properties has confirmed a possibility of the retrievals of single scattering albedo and asymmetry factor from AERONET inversion products and its extrapolation to UV range using the Mie theory in the absence of fire conditions.

It should be emphasized that the obtained spatial distribution of aerosol parameters can be used for the description of the latest period, since, as it is mentioned in the Introduction, there are the pronounced negative trends in aerosol optical thickness of about $-0.04-0.05$ per decade since 1980s.

The estimates of UV irradiance reduction due to aerosol have been obtained for different seasons. It has been shown that the absolute loss of UV indices due to a positive correlation with both aerosol optical thickness and solar elevation is most pronounced over southern areas. The $\Delta$ UVI varies from less than 0.1 over the northern areas in winter up to 1.5 over polluted areas at the south (Northern Italy). However, significant variations in $\Delta \mathrm{UVI}$ (within the order of magnitude) can be observed only due to $\tau_{\lambda}$ variations, especially at the south of Europe.

The analysis of relative changes in $Q_{e}$ due to aerosol has revealed large spatial and temporal variations within $\sim-1-$ $-17 \%$ with minimum $Q_{e}$ attenuation (>-3\%) during cold period over the North Atlantic area, Scandinavia, etc. The most significant $Q_{e}$ loss $(-15--17 \%)$ was estimated over Northern Italy in spring and in autumn due to high aerosol loading and lower solar elevations compared with summer conditions. In winter the $Q_{e}$ attenuation over Europe varies within $10 \%$ and increases on $3-5 \%$ over the polluted centers. In spring and summer $Q_{e}$ attenuation can reach -10 $15 \%$ over the Central, Eastern and North-Eastern Europe. In autumn, there is a pronounced decrease in $Q_{e}$ loss over the whole European territory, except Northern Italy.
Due to the existence of different dependence on solar elevation one can see a pronounced shift to the north for the relative $Q_{e}$ attenuation and to the south for the absolute $Q_{e}$ attenuation.

The effects of aerosol loading on UV irradiance can be compared with total ozone influence. The same aerosol loading at high latitudes can provide much stronger relative changes in $Q_{e}$ while there is vice versa situation with total ozone, which has less effects on $Q_{e}$ at low elevations (high latitudes) than at low latitudes (see, for example, Fioletov et al., 2001). In other words, in spring at high latitudes the potential UVI growth due to the total ozone decrease can be much more effectively cancelled by the aerosol loading. In addition, at high latitudes the $Q_{e}$ variations due to aerosol are much more pronounced and can significantly influence the $Q_{e}$ year-to-year variability, that should be taken into account while revealing the ozone component in $Q_{e}$ long-term trend. This is possible to fulfill, using spectral measurements as described for example, in Glandorf et al. (2004).

Acknowledgements. The paper was inspired by the tasks of the COST 726 Action "Long term changes and climatology of UV radiation over Europe". The author wishes to thank the MODIS and AERONET/PHOTONS aerosol team for support in accessing and using their data products. I would like to thank the PI investigators of the AERONET/PHOTONS and their staff for establishing and maintaining all the sites over Europe and nearby territories, which were used in this investigation. MODIS data were produced with the Giovanni online data system, developed and maintained by the NASA Goddard Earth Sciences (GES) Data and Information Services Center (DISC). The work has been partially supported by the RSFBR grants \#07-05-00860, and \#09-05-00582.

Edited by: A. A. Kokhanovsky

\section{References}

Andreae, M. O. and Crutzen, P. J.: Atmospheric Aerosols: Biogeochemical Sources and Role in Atmospheric Chemistry, Science, 276, 1052-1058, 1997.

Arola, A., Lakkala, K., Bais, A., Kaurola, J., Meleti, C., and Taalas, P.: Factors affecting short- and long-term changes of spectral UV irradiance at two European stations, J. Geophys. Res., 108(D17), 4549, doi:10.1029/2003JD003447, 2003.

Badosa, J., McKenzie, R. L., Kotkamp, M., Calbó, J., González, J. A., Johnston, P. V., O'Neill, M., and Anderson, D. J.: Towards closure between measured and modelled UV under clear skies at four diverse sites, Atmos. Chem. Phys., 7, 2817-2837, 2007, http://www.atmos-chem-phys.net/7/2817/2007/.

Bais, A. F., Kazantzidis, A., Kazadzis, S., Balis, D. S., Zerefos, C. S., and Meleti, C.: Deriving an effective aerosol single scattering albedo from spectral surface UV irradiance measurements, Atmos. Environ., 39(6), 1093-1102, 2005.

Balis, D. S., Amiridis, V., Zerefos, C., Kazantzidis, A., Kazadzis, S., Bais, A. F., Meleti, C., Gerasopoulos, E., Papayannis, A., Matthias, V., Dier, H., and Andreae, M. O.: Study of the effect of different type of aerosols on UV-B radiation from measurements 
during EARLINET, Atmos. Chem. Phys., 4, 307-321, 2004, http://www.atmos-chem-phys.net/4/307/2004/.

Chubarova, N. Y. and Sviridenkov, M. A.: The differences in optical thicknesses due to aerosol and $\mathrm{NO}_{2}$ signatures obtained from parallel CIMEL sun photometers measurements in Moscow and at Zvenigorod, Preprint of IAE-6506/16, The Publishing House of Russian Research Centre "Kurchatov Institute", Moscow, 45$51,2008$.

Chubarova, N. Y., Nezval, Y. I., Verdebout, J., Krotkov, N., and Herman, J.: Long-term UV irradiance changes over Moscow and comparisons with UV estimates from TOMS and METEOSAT, in: Ultraviolet Ground- and Space-based Measurements, Models, and Effects V, edited by: Bernhard, G., Slusser, J.R., Herman, J.R., and Gao, W., SPIE, 63-73, 2005.

Chubarova, N. Y., Prilepsky, N. G., Rublev, A. N., and Riebau, A. R.: A Mega-Fire Event in Central Russia: Fire Weather, Radiative, and Optical Properties of the Atmosphere, and Consequences for Subboreal Forest Plants, in: Developments in Environmental Science, edited by: Bytnerowicz, M., Arbaugh, A., Riebau, A., and Andersen, C., Elsevier B. V., Volume 8249 A, 249-267, 2009.

Chubarova, N. Y.: UV variability in Moscow according to longterm UV measurements and reconstruction model, Atmos. Chem. Phys., 8, 3025-3031, 2008,

http://www.atmos-chem-phys.net/8/3025/2008/.

Denman, K. L., Brasseur, G., Chidthaisong, A., Ciais, P., Cox, P. M., Dickinson, R. E., Hauglustaine, D., Heinze, C., Holland, E., Jacob, D., Lohmann, U., Ramachandran, S., da Silva Dias, P. L., Wofsy, S. C., and Zhang, X.: Couplings Between Changes in the Climate System and Biogeochemistry, in: Climate Change 2007: The Physical Science Basis, Contribution of Working Group I to the Fourth Assessment Report of the Intergovernmental Panel on Climate Change, edited by: Solomon, S., Qin, D., Manning, M., Chen, Z., Marquis, M., Averyt, K. B., Tignor, M., and Miller, H. L., Cambridge University Press, Cambridge, UK and New York, NY, USA, 2007.

Dubovik, O. and King, M. D.: A flexible inversion algorithm for retrieval of aerosol optical properties from Sun and sky radiance measurements, J. Geophys. Res., 105(D16), 20673-20696, 2000.

Dubovik, O., Smirnov, A., Holben, B. N., King, M. D., Kaufman, Y. J., Eck, T. F., and Slutsker, I.: Accuracy assessments of aerosol optical properties retrieved from Aerosol Robotic Network (AERONET) Sun and sky radiance measurements, J. Geophys. Res., 105(D8), 9791-9806. 2000.

Dubovik, O., Holben, B. N., Eck, T. F., Smirnov, A., Kaufman, Y. J., King, M. D., Tanre, D., and Slutsker, I.: Variability of absorption and optical properties of key aerosol types observed in worldwide locations, J. Atmos. Sci., 59, 590-608, 2002.

Eck, T., Holben, B., Reid, J., Dubovik, O., Smirnov, A., O’Neill, N., Slutsker, I., and Kinne, S.: Wavelength dependence of the optical depth of biomass burning, urban, and desert dust aerosols, J. Geophys. Res., 104(D24), 31333-31349, 1999.

Fioletov, V., McArthur, L., Kerr, J., and Wardle, D.: Long-term variations of UV-B irradiance over Canada estimated from Brewer observations and derived from ozone and pyranometer measurements, J. Geophys. Res., 106(D19), 23009-23027, 2001.

Früh, B., Eckstein, E., Trautmann, T., Wendisch, M., Fiebig, M., and Feister, U.: Ground-based measured and calculated spectra of actinic flux density and downward UV irradiance in cloudless conditions and their sensitivity to aerosol microphysical properties, J. Geophys. Res., 108(D16), 4509, doi:10.1029/2002JD002933, 2003.

Glandorf, M., Arola, A., Bais, A., and Seckmeyer, G.: Possibilities to detect trends in spectral UV irradiance, Theor. Appl. Climatol., 81(1-2), 33-44, 2005.

Gorbarenko, E. V., Yerokhina, E., and Lukin, A. B.: Long- Period changes in Aerosol Optical Thickness of the Atmosphere in Russia, Russ. Meteorol. Hydrol., 7, 25-31. 2006.

Holben, B. N., Eck, T. F., Slutsker, I., Tanre, D., Buis, J. P., Setzer, A., Vermote, E., Reagan, J. A., Kaufman, Y. J., Nakajima, T., Lavenu, F., Jankowiak, I., and Smirnov, A.: AERONET - A federated instrument network and data archive for aerosol characterization, Remote Sens. Environ., 66, 1-16, 1998.

IPCC Climate Change 2007: The Physical Science Basis, Contribution of Working Group I to the Fourth Assessment Report of the Intergovernmental Panel on Climate Change, edited by: Solomon, S., Qin, D., Manning, M., Chen, Z., Marquis, M., Averyt, K. B., Tignor, M., and Miller, H. L., Cambridge University Press, Cambridge, UK and New York, NY, USA, 2007.

Janowiak, J. E. and Xie, P.: CAMS_OPI: A Global Satellite-Rain Gauge Merged Product for Real-Time Precipitation Monitoring Applications, J. Climate, 12, 3335-3342, 1999.

Kalnay, E., Kanamitsu, M., Kistler, R., Collins, W., Deaven, D., Gandin, L., Iredell, M., Saha, S., White, G., Woollen, J., Zhu, Y., Leetmaa, A., Reynolds, B., Chelliah, M., Ebisuzaki, W., Higgins, W., Janowiak, J., Mo, K. C., Ropelewski, C., Wang, J., Jenne, R., and Joseph, D.: The NCEP/NCAR 40-Year Reanalysis Proct, B. Am. Meteorol. Soc., March, 1996.

Jaroslawski, J. P. and Krzy'scin, J. W.: Importance of aerosol variations for surface UV-B level: Analysis of ground-based data taken at Belsk, Poland, 1992-2004, J. Geophys. Res., 110, D16201, doi:10.1029/2005JD005951, 2005.

Kazadzis, S., Bais, A., Amiridis, V., Balis, D., Meleti, C., Kouremeti, N., Zerefos, C. S., Rapsomanikis, S., Petrakakis, M., Kelesis, A., Tzoumaka, P., and Kelektsoglou, K.: Nine years of UV aerosol optical depth measurements at Thessaloniki, Greece, Atmos. Chem. Phys., 7, 2091-2101, 2007, http://www.atmos-chem-phys.net/7/2091/2007/.

Koukouli, M. E., Kazadzis, S., Amiridis, V., Ichoku, C., and Balis, D. S.: Comparisons of Satellite Derived Aerosol Optical Depth Over a Variety of Sites in the Southern Balkan Region as an Indicator of Local Air Quality, Remote Sensing of Clouds and the Atmosphere XII, edited by: Comerón, A., Picard, R. H., Schäfer, K., Slusser, J. R., and Amodeo, A., Proc. of SPIE, 67451V-1,, doi:10.1117/12.737681, 2007.

Krotkov, N., Bhartia, P. K., Herman, J., Slusser, J., Scott, G., Labow, G., Vasilkov, A. P., Eck, T. F., Dubovik, O., and Holben, B. N.: Aerosol ultraviolet absorption experiment (2002 to 2004), part 2: absorption optical thickness, refractive index, and single scattering albedo, Opt. Eng., 44, 041005; doi:10.1117/1.1886819, 2005.

Madronich, S. and Flocke, S.: The role of solar radiation in atmospheric chemistry, in: Handbook of environmental chemistry, Springer-Verlag, Heidelberg, 1-26, 1998.

Makhotkina, E. L., Plakhina, I. N., and Lukin, A. B.: Some features of Atmospheric turbidity change over the Russian territory in the last quarter of the 20th century, Russ. Meteorol. Hydrol., Allerton Press, 1, 20-27, 2005. 
McKenzie, R., Seckmeyer, G., Bais, A. F., Kerr, J. B., and Madronich, S.: Satellite retrievals of erythemal UV dose compared with ground-based measurements at northern and southern midlatitudes, J. Geophys. Res., 106, 24051-24062, 2001.

Myachkova, N. A.: Climates of the USSR, Moscow University Publishing House, 192, 1983.

Remer, L. A., Kleidman, R. G., Levy, R. C., Kaufman, Y. J., Tanré, D., Mattoo, S., Martins, J. V., Ichoku, C., Koren, I., Yu, H., and Holben, B. N.: Global aerosol climatology from the MODIS satellite sensors, J. Geophys. Res., 113, D14S07, doi:10.1029/2007JD009661, 2008.

Ruckstuhl, C., Philipona, R., Behrens, K., Coen, M., Dürr, B., Heimo, A., Ma“tzler, C., Nyeki, S., Ohmura, A., Vuilleumier, L., Weller, M., Wehrli, C., and Zelenka, A.: Aerosol and cloud effects on solar brightening and the recent rapid warming Geophysical Research Letters, 35, L12708, doi:10.1029/2008GL034228, 2008.

Schaap, M., Renske, M. A., Timmermans, R. M. A., Roemer, M., Boersen, G. A. C., Builtjes, P., Sauter, F., Velders, G., and Beck, J.: The LOTOS-EUROS model: description, validation and latest developments, Int. J. Environ. Pollut., 32(2), 270-290, 2008.
Seckmeyer, G., Bais, A., Bernhard, G., Blumthaler, M., Booth, C. R., Lantz, K., and McKenzie, R. L.: Instruments to measure solar ultraviolet irradiance, Part 2: Broadband instruments measuring erythemally weighted solar irradiance, WMO, Global Atmospheric Watch No. WMO TD, 1289, 51, 2006.

Smirnov, A., Holben, B. N., Kaufman, Y. J., Dubovik, O., Eck, T. F., Slutsker, I., Pietras, C., and Halthore, R.: Optical Properties of Atmospheric Aerosol in Maritime Environments, J. Atmos. Sci., 59, 501-523, 2002.

Smirnov, A., Holben, B. N., Dubovik, O., O’Neill, N. T., Remer, L. A., Eck, T. F., Slutsker, I., and Savoie, D.: Measurement of atmospheric optical parameters on US Atlantic coast sites, ships and Bermuda during TARFOX, J. Geophys. Res., 105, 98879901, 2000.

Torres, O., Bhartia, P. K., Herman, J. R., Sinyuk, A., Ginoux, P., and Holben, B.: A long-term record of aerosol optical depth from TOMS observations and comparison to AERONET measurements, J. Atmos. Sci., 59, 398-413, 2002.

Van der Leun, J. C., Tang, X., and Tevini, M.: Environmental effects of ozone depletion 1998 Assessment, Executive summary, in the book "Environmental effects of ozone depletion 1998 Assessment”, J. Photoch. Photobio. B, 46, 103, 1998.

Vanicek, K., Frei, T., Litynska, Z., and Shmalwieser, A.: UV-Index for the Public, COST-713 Action, Brussels, 2000. 